\title{
Global magnetospheric response to an interplanetary shock: THEMIS observations
}

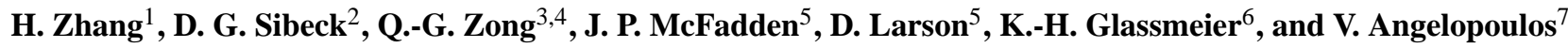 \\ ${ }^{1}$ Geophysical Institute, University of Alaska Fairbanks, AK, USA \\ ${ }^{2}$ NASA Goddard Space Flight Center, Greenbelt, MD, USA \\ ${ }^{3}$ Center for Atmospheric Research, University of Massachusetts, Lowell, USA \\ ${ }^{4}$ Institute of Space Physics and Applied Technology, Peking University, Beijing, China \\ ${ }^{5}$ Space Sciences Laboratory, University of California, Berkeley, CA, USA \\ ${ }^{6}$ Institute for Geopysics and Extraterrestrial Physics, TU Braunschweig, Germany \\ ${ }^{7}$ IGPP/ESS UCLA, Los Angeles, CA 90095-1567, USA
}

Correspondence to: H. Zhang (hzhang@gi.alaska.edu)

Received: 21 July 2011 - Revised: 3 January 2012 - Accepted: 8 February 2012 - Published: 22 February 2012

\begin{abstract}
We investigate the global response of the geospace plasma environment to an interplanetary (IP) shock at $\sim 02: 24$ UT on 28 May 2008 from multiple THEMIS spacecraft observations in the magnetosheath (THEMIS B and C), the mid-afternoon magnetosphere (THEMIS A), and the dusk magnetosphere (THEMIS D and E). The interaction of the transmitted IP shock with the magnetosphere has global effects. Consequently, it can affect geospace plasma significantly. After interacting with the bow shock, the IP shock transmitted a fast shock and a discontinuity which propagated through the magnetosheath toward the Earth at speeds of $301 \mathrm{~km} \mathrm{~s}^{-1}$ and $137 \mathrm{~km} \mathrm{~s}^{-1}$, respectively. THEMIS A observations indicate that the IP shock changed the properties of a plasmaspheric plume significantly. The plasmaspheric plume density increased rapidly from 10 to $100 \mathrm{~cm}^{-3}$ in $4 \mathrm{~min}$ and the ion distribution changed from an isotropic to a strongly anisotropic distribution. Electromagnetic ion cyclotron (EMIC) waves observed by THEMIS A are most likely excited by the anisotropic ion distributions caused by the IP shock impact. THEMIS A, but not D or E, observed a plasmaspheric plume in the dayside magnetosphere. Multiple spacecraft observations indicate that the dawn-side edge of the plasmaspheric plume was located between THEMIS A and $\mathrm{D}$ (or E).
\end{abstract}

Keywords. Interplanetary physics (Interplanetary shocks) Magnetospheric physics (Magnetospheric configuration and dynamics; Solar wind-magnetosphere interactions)

\section{Introduction}

The interaction of interplanetary (IP) shocks (usually fast forward shocks) with the magnetosphere includes several phases, including interaction with the bow shock, transmission through the magnetosheath, interaction with the magnetopause, transmission into the magnetosphere as fast and intermediate mode waves, modifications of the field-aligned and ionospheric current systems, and perturbations in ground magnetograms (Samsonov et al., 2007). The interaction of IP shocks with the bow shock has been extensively studied (e.g., Shen and Dryer, 1972; Grib et al., 1979; Zhuang et al., 1981; Samsonov et al., 2006, 2007; Zhang et al., 2009). In MHD simulations, the interaction of an IP shock with the bow shock launches a fast shock into the magnetosheath and creates a new discontinuity (Zhuang et al., 1981) where the magnetic field strength and density increase, the temperature decreases and the velocity remains unchanged (Samsonov et al., 2006). The transmitted fast shock and new discontinuity have been observed (Šafránková et al., 2007; Přech et al., 2008).

Past work has predicted that the interaction of an IP shock, marked by a pressure increase, with the bow shock results in earthward then sunward motion of the bow shock. By analyzing the Rankine-Hugoniot conditions, Grib et al. (1979) and Völk and Auer (1974) predicted that the bow shock moves towards the magnetosphere after interaction with the IP shock. Then the interaction of the transmitted fast shock and the magnetopause (considered as a tangential discontinuity) results in a fast rarefaction wave propagating toward the 
bow shock. This rarefaction wave could result in outward bow shock motion. In MHD simulations, the bow shock begins moving earthward immediately after an encounter with an IP shock at velocities of $\sim 100 \mathrm{~km} \mathrm{~s}^{-1}$ (Samsonov et al., 2006). Results from a three-dimensional magnetosheath numerical model show that both a fast reverse shock and a fast expansion wave (rarefaction wave) may result from the interaction of the IP shock with the magnetopause depending on boundary conditions of the model (Samsonov et al., 2006). The existence of the rarefaction wave reflected from the magnetopause due to the shock-magnetopause interaction was confirmed by a case study employing observations made by Cluster spacecraft in the magnetosheath (Maynard et al., 2008). Based on results from global MHD simulations, Samsonov et al. (2007) suggested that the dayside ionosphere reflects the transmitted fast shock and that the bow shock and the magnetopause move sunward when the reflected fast shock passes. Earthward then sunward bow shock motion due to the interaction of an IP shock with the bow shock has been observed (e.g., Šafránková et al., 2007). Šafránková et al. (2007) concluded that the observed bow shock crossings result from the IP shock-magnetosphere interactions because there are no further changes in the upstream dynamic pressure or IMF that could cause them.

Electromagnetic ion cyclotron (EMIC) waves are generated by the ion temperature anisotropy $\left(T_{\perp}>T_{\|}\right)$(e.g., Cornwall, 1965). The frequency of EMIC waves is below the local proton gyrofrequency. In the magnetosphere, it ranges from 0.1 to $5 \mathrm{~Hz}$. EMIC waves in the hydrogen band (with frequencies between the helium and hydrogen gyrofrequencies) and helium band (with frequencies between the oxygen and helium gyrofrequencies) are often observed in the magnetosphere (Young et al., 1981; Roux et al., 1982; Anderson et al., 1992). Their highest occurrence is in the dayside magnetosphere beyond $L=7$ (Anderson et al., 1990, 1992). EMIC waves have been found to be often associated with compressions (Anderson and Hamilton, 1993; Engebretson et al., 2002; Usanova et al., 2008).

The plasmasphere is a region located in the dipolar portions of the Earth's magnetosphere and populated by cold $(\sim \mathrm{eV})$ and dense plasma of ionospheric origin (Lemaire and Gringauz, 1998; Darrouzet et al., 2009a; Singh et al., 2011). Plasmaspheric plumes are large-scale density structures that are usually connected to the main body of the plasmasphere, and extend outward (e.g., Elphic et al., 1996; Ober et al., 1997; Sandel et al., 2001). Plasmaspheric plumes have been detected by in-situ and ground-based instruments (e.g., Chappell et al., 1970; Carpenter et al., 1992; Foster et al., 2002; Moldwin et al., 2004; Goldstein et al., 2004; Darrouzet et al., 2006, 2009b). Dense $\left(>10 \mathrm{~cm}^{-3}\right)$ plasmaspheric plumes and/or cold ions at the magnetopause have been observed (Chappell, 1974; Gosling et al., 1990; McFadden et al., 2008a). Darrouzet et al. (2008) presented a statistical analysis of the plasmaspheric plumes observed by the Cluster spacecraft. They found that plasmaspheric plumes were observed mostly for moderate $\mathrm{Kp}$ and not for small Dst. They also showed that plumes are mainly located in the afternoon and pre-midnight MLT sectors. Plasmaspheric plumes have been suggested as a major cause of EMIC waves (Fuselier et al., 2004).

Most of the previous studies on EMIC waves and plasmaspheric plumes were during magnetic storms or substorms. In this paper, we investigate the global response of the geospace plasma environment to an IP shock from multiple THEMIS spacecraft observations in the magnetosheath (THEMIS B and C), the mid-afternoon magnetosphere (THEMIS A), and the dusk magnetosphere (THEMIS D and E). The outline of this paper is as follows. Section 2 presents observations from the WIND and THEMIS spacecraft. Section 3 concludes the paper.

\section{Spacecraft observations}

Figure 1 shows an IP shock observed by the WIND spacecraft located at $(x, y, z)=(257,52,23)$ GSE $R_{\mathrm{E}}$. Panels (a)(c) show plasma moments measured by Solar Wind Experiment (SWE) with 1 min time resolution (Ogilvie et al., 1995). Panel (d) shows the calculated dynamic pressure $\left(n m v^{2}\right)$. Panels (e) and (f) show magnetic fields measured by Magnetic Field Investigation (MFI) instrument with $3 \mathrm{~s}$ time resolution (Lepping et al., 1995). The interplanetary magnetic field (IMF) was southward from 01:00 to 01:12 UT and from 01:18 to 01:25 UT, mainly northward from 01:12 to $01: 18 \mathrm{UT}$ and after $01: 25 \mathrm{UT}$. The vertical dashed red line at 01:17:38 UT marks the IP shock crossing which is clearly defined from the magnetic field strength variation. The IP shock is a fast forward shock which is characterized by increases in the solar wind density, thermal temperature, bulk velocity, dynamic pressure and magnetic field strength.

The plasma observations reported below were obtained from the Electrostatic Analyzer (ESA) (McFadden et al., 2008b) on the THEMIS spacecraft (Angelopoulos, 2008). In one 3-s spin, ESA measures the 3-D ion and electron distributions over the energy range from a few $\mathrm{eV}$ up to $30 \mathrm{keV}$ for electrons and up to $25 \mathrm{keV}$ for ions. The magnetic field observations presented herein are obtained by the Fluxgate Magnetometer (FGM) (Auster et al., 2008) which measures the DC magnetic field up to $128 \mathrm{~Hz}$.

Figure 2 shows the trajectories of the THEMIS spacecraft (small colored lines) from 02:00 UT to 03:00 UT on 28 May 2008. Five different symbols in Fig. 2 mark the positions of 5 THEMIS probes at 03:00 UT. THEMIS B and C are in the magnetosheath and THEMIS D, E, and A are inside the magnetosphere at 02:20 UT. These regions can be identified from the ion spectra in Fig. 3d, h, j, 1 and n. THEMIS D and $E$ are very close to each other on the dusk flank.

The IP shock observed by WIND (shown in Fig. 1) propagated toward the Earth and was observed by the THEMIS spacecraft. Panels (a)-(d) in Fig. 3 show THEMIS B 


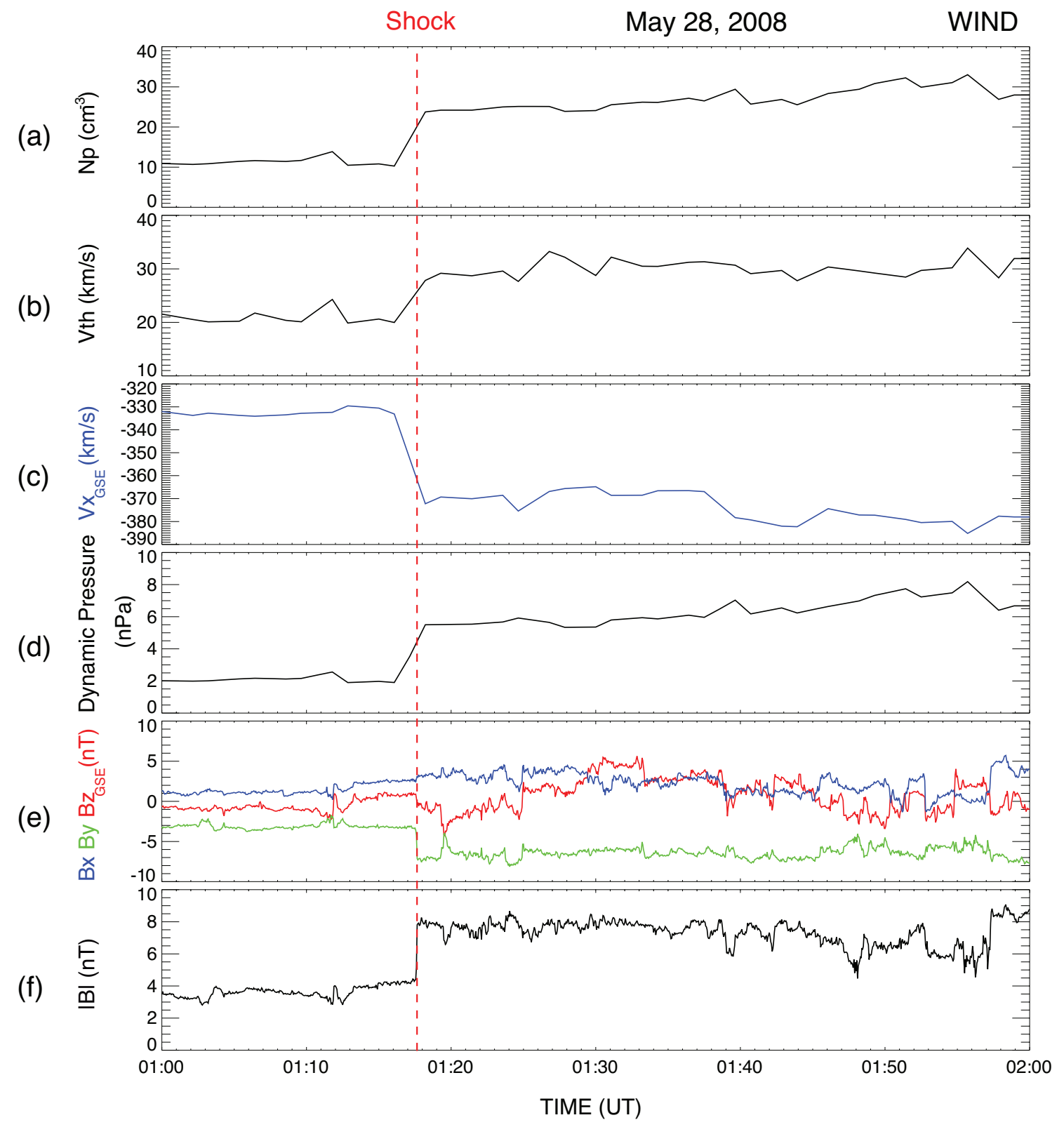

Fig. 1. An IP shock observed by the WIND spacecraft upstream at $(257,52,23) R_{\mathrm{E}}$. From top to bottom: (a) ion density, (b) thermal velocity, (c) component of the flow velocity $V_{\mathrm{X}}$ along the Sun-Earth line, (d) dynamic pressure, (e) components of the magnetic fields in GSE coordinates, and (f) the magnetic field strength. The vertical dashed red line at 01:17:38 UT marked the IP shock crossing.

observations and panels (e)-(h) show THEMIS C observations. Panels (i)-(n) show observations by THEMIS D, E and A. The IP shock first reached THEMIS B in the magnetosheath. Panel (a) shows the plasma flow $V_{\mathrm{X}}$ component. Panel (b) shows the ion density. Panel (c) shows the ion temperature. Panel (d) shows the ESA plasma ion spectrum. The bow shock moved inward past THEMIS B at 02:25:07 UT, as indicated by the transition to low solar wind densities and temperatures but high velocities. The black dashed line at 02:23:47 UT marks the transmitted fast shock (due to the in- teraction between the IP shock and the bow shock) which can be identified by increases in the plasma flow speed, density and temperature. This shock was followed by a discontinuity at 02:24:04 UT which is characterized by a density increase and a temperature decrease. This is the new discontinuity predicted by MHD theory (Samsonov et al., 2006). Both the transmitted fast shock and the new discontinuity propagated earthward towards THEMIS C. The separation between the shock and discontinuity observed by THEMIS C at 02:24:16 UT and 02:25:42 UT is larger than that observed 


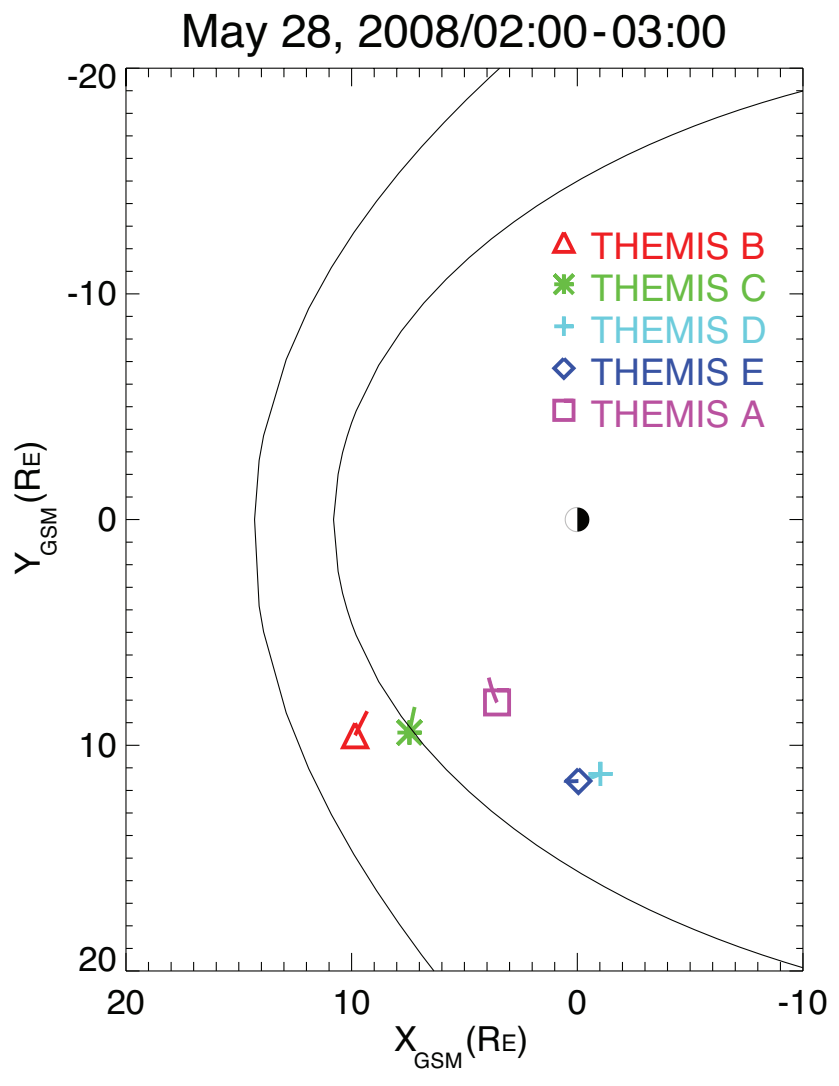

Fig. 2. THEMIS trajectories (small colored lines) projected in the GSM X-Y plane from 02:00 to 03:00 UT on 28 May 2008. The two black curves represent the location of the bow shock and magnetopause determined by the Fairfield model (Fairfield, 1971). The positions of 5 THEMIS probes at 03:00 UT are marked by 5 different symbols. THEMIS $\mathrm{B}$ and $\mathrm{C}$ are in the magnetosheath and THEMIS D, E, and A are inside the magnetosphere at 02:20 UT, which can be identified from the ion spectra in Fig. 3d, h, j, 1 and n. THEMIS D and E are very close to each other on the dusk flank. At 02:25 UT, THEMIS B is located at $(9.5,8.9,-3.5)$ GSM $R_{\mathrm{E}}$, THEMIS $\mathrm{C}$ is located at $(7.3,8.8,-1.9)$ GSM $R_{\mathrm{E}}$, THEMIS A is located at $(3.8,7.5,-1.1)$ GSM $R_{\mathrm{E}}$, THEMIS D and E are located at $(-0.7,11.4,0.6) \mathrm{GSM} R_{\mathrm{E}}$ and $(0.3,11.6,0.2) \mathrm{GSM} R_{\mathrm{E}}$, respectively.

by THEMIS B at 02:23:47 UT and 02:24:04 UT due to the greater propagation speed of the shock than the discontinuity. Parameters of the transmitted shock and the new discontinuity have been calculated using Shock and Discontinuities Analysis Tool (SDAT) (Viñas and Holland, 2005) which uses the Viñas-Scudder analysis method (Viñas and Scudder, 1986) based on the Rankine-Hugoniot conservation equations. This method has been used by (Zhang et al., 2009). The normal direction of the transmitted shock is $(-0.90$, $-0.10,-0.43)$ GSE and the shock velocity along the shocknormal direction is $301 \pm 27 \mathrm{~km} \mathrm{~s}^{-1}$. The normal direction of the new discontinuity is $(-0.96,-0.22,-0.20)$ GSE and the propagation velocity along the normal direction is
$137 \pm 20 \mathrm{~km} \mathrm{~s}^{-1}$. The propagation velocities of the transmitted fast shock and the new discontinuity can also be calculated using the separation of THEMIS B and C along the normal directions divided by the time delay between these two spacecraft (timing method). THEMIS B was located at $(9.5,7.7,-5.8)$ GSE $R_{\mathrm{E}}$ and THEMIS $\mathrm{C}$ was located at $(7.3,8.0,-4.2)$ GSE $R_{\mathrm{E}}$ at $02: 25 \mathrm{UT}$. The propagation velocities of the transmitted fast shock and the new discontinuity obtained from the timing method are $278 \mathrm{~km} \mathrm{~s}^{-1}$ and $112 \mathrm{~km} \mathrm{~s}^{-1}$, respectively, which are consistent with the results using SDAT. The dynamic pressure increases associated with the transmitted fast shock then compressed the magnetosphere. THEMIS D, E and A inside the magnetosphere observed antisunward-moving plasmas beginning at almost the same times (marked by black dashed lines in panels $\mathrm{i}, \mathrm{k}$ and $\mathrm{m}$ ), and lasting for at least $2 \mathrm{~min}$.

Figure 4 shows THEMIS A observations from 02:20 to 03:10 UT, 28 May 2008. Panel (a) shows three components of the magnetic field in GSM coordinates with $0.25 \mathrm{~s}$ time resolution. The magnetic field strength (panel b) increased sharply from $60 \mathrm{nT}$ to $75 \mathrm{nT}$ at $\sim 02: 25 \mathrm{UT}$ due to the pressure enhancement associated with the IP shock. Then the magnetic field strength decreased slowly to $68 \mathrm{nT}$ at 02:34 UT. The magnetic field strength showed a few more compressions and relaxations with a $\sim 5 \mathrm{~min}$ period from $02: 43$ to 02:57 UT. Panel (c) shows the x-component of the plasma flow velocity in GSM coordinates. After the IP shock arrival (at $\sim 02: 24 \mathrm{UT}$ ), the $V_{\mathrm{x}}$ component turned antisunward and then oscillated around 0 with an amplitude of $\sim 50 \mathrm{~km} \mathrm{~s}^{-1}$ from 02:24 to 03:10 UT. The amplitude of the oscillating electric field $E_{\mathrm{y}}$ measured by the Electric Field Instrument (EFI) (Bonnell et al., 2008) was $5 \mathrm{mV} \mathrm{m}^{-1}$ (not shown). Panel (d) shows the wavelet analysis result for the $B_{\mathrm{y}}$ component of the magnetic field. The black (magenta) line at around $0.25 \mathrm{~Hz}(0.03 \mathrm{~Hz})$ shows the gyrofrequency of Helium (Oxygen) ions. The strong emissions with frequencies between the gyrofrequencies of the Helium and Oxygen ions are EMIC waves. Panel (e) shows the ESA ion spectrum. An interesting feature is the sporadic measurement of a very cold plasma $(\sim 10 \mathrm{eV})$ from $02: 25$ to $02: 26 \mathrm{UT}$, from $02: 32$ to $02: 36 \mathrm{UT}$, from 02:47 to $02: 49 \mathrm{UT}$, and from 02:57 to 02:59 UT. The cold ions appear when there is a substantial plasma flow $V_{\mathrm{x}}$ component. The cold ions are accelerated plasmaspheric plume populations. Panel (f) shows the plasma density inferred from the spacecraft potential and electron thermal speed measured by the EFI and ESA instruments, respectively, including both the cold population (measured by EFI) and the hot component (measured by ESA). Details of the method are described by Mozer (1973). This method has been used by Li et al. (2010); Takahashi et al. (2010), and confirmed that the spacecraft potential can be used to reliably estimate the plasma density. The density $n_{\text {pot }}$ shown in panel (f) has been compared with the ESA electron density moment (not shown). The ESA electron density moment is smaller (due to the limited measurable 


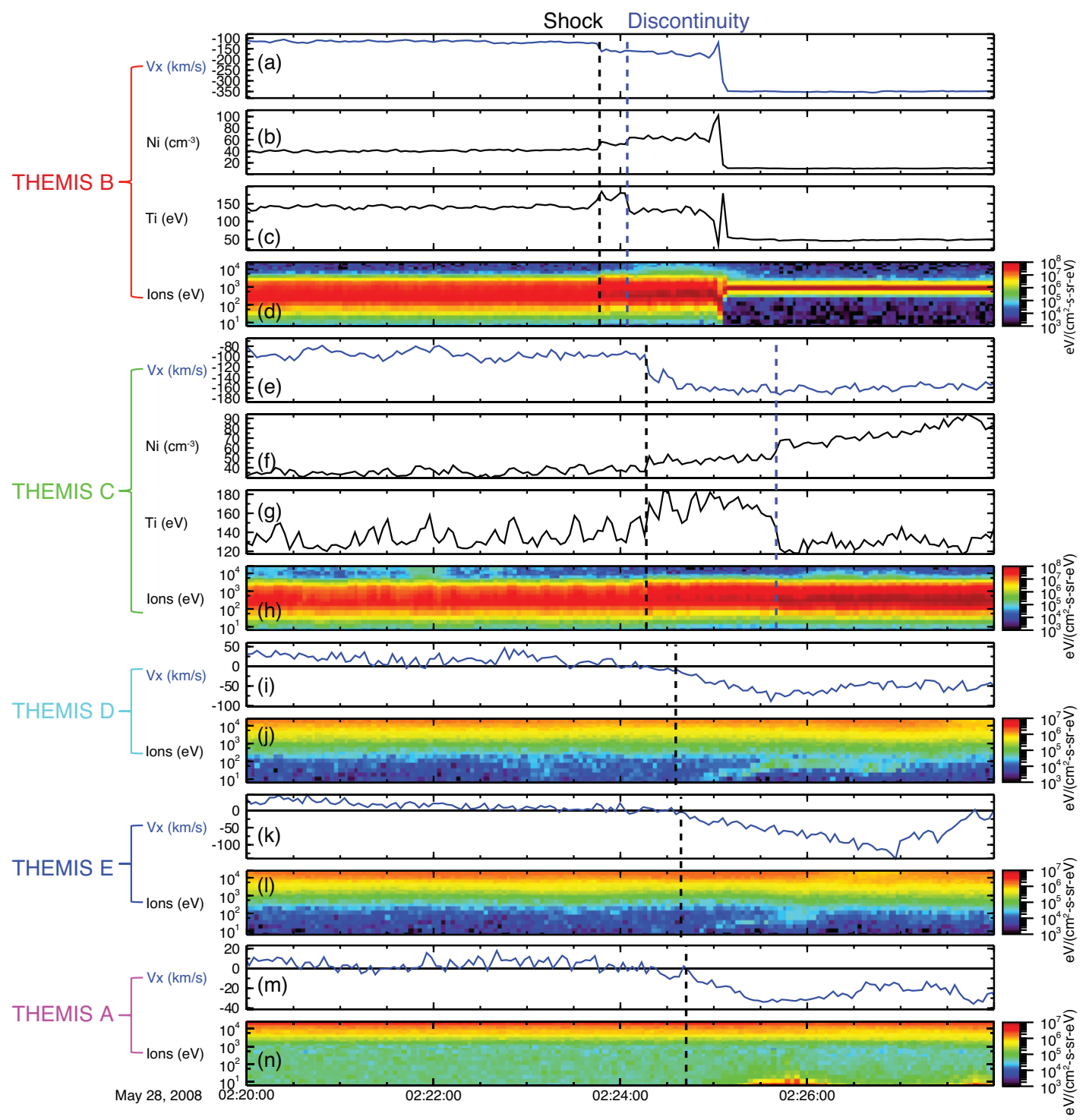

Fig. 3. The propagation of the IP shock through the magnetosheath and in the magnetosphere. From top to bottom: (a)-(d) THEMIS B ESA plasma flow $V_{\mathrm{X}}$ component, ion density, temperature, spectrum, (e)-(h) THEMIS C ESA plasma flow $V_{\mathrm{x}}$ component, ion density, temperature, spectrum, (i) and (j) THEMIS D ESA plasma flow $V_{\mathrm{X}}$ component, ion spectrum, (k) and (l) THEMIS E ESA plasma flow $V_{\mathrm{X}}$ component, ion spectrum, (m) and (n) THEMIS A ESA plasma flow $V_{\mathrm{X}}$ component, ion spectrum. The bow shock crossing was observed by THEMIS B near 02:25 UT. The vertical black dashed lines mark the transmitted shock (top 8 panels) or the time when the plasma inside the magnetosphere started to move earthward (bottom 6 panels). The vertical blue dashed lines in the top 8 panels mark the discontinuity produced by the interaction of the IP shock and the bow shock.

energy range) but overall follows $n_{\text {pot }}$, indicating that $n_{\text {pot }}$ shows real changes. Before the shock passage at 02:25 UT, the total density $n_{\text {pot }}$ was $10 \mathrm{~cm}^{-3}$ and the ESA electron density was $1 \mathrm{~cm}^{-3}$ (not shown). Therefore, the density of the cold population is $9 \mathrm{~cm}^{-3}$, indicating that THEMIS A most probably observed a plasmaspheric plume (e.g., Goldstein et al., 2004; Zhang et al., 2011). The density increased to $30 \mathrm{~cm}^{-3}$ at $02: 26 \mathrm{UT}$ and $100 \mathrm{~cm}^{-3}$ at $02: 29 \mathrm{UT}$. The density drop from 5 to $0.5 \mathrm{~cm}^{-3}$ observed by THEMIS A at $(3.6,8.1$, -1.3) GSM $R_{\mathrm{E}}$ indicates the dusk-side edge of the plume was located at $(3.6,8.1,-1.3) \mathrm{GSM} R_{\mathrm{E}}$ at 03:00 UT.
The EMIC wave activity seems to be closely related to the accelerated plasmaspheric plume population from panels (d) and (e) of Fig. 4. Ion temperature anisotropies can stimulate EMIC waves in the frequency range $\omega / \Omega_{i}<A_{\mathrm{i}} /\left(1+A_{\mathrm{i}}\right)$ (Horne and Thorne, 1993), where $\Omega_{i}$ is the ion gyrofrequency, and $A_{\mathrm{i}}$ is the ion temperature anisotropy which is defined by $A_{\mathrm{i}}=T_{\perp} / T_{\|}-1$. Panel (g) of Fig. 4 presents ion distributions in the $V_{\text {perp }}-V_{\text {para }}$ (relative to the magnetic field) plane for $3 \mathrm{~s}$ time intervals before (left) and after (right) the shock arrival. The ion distribution before the shock arrival was nearly isotropic, whereas it was strongly 


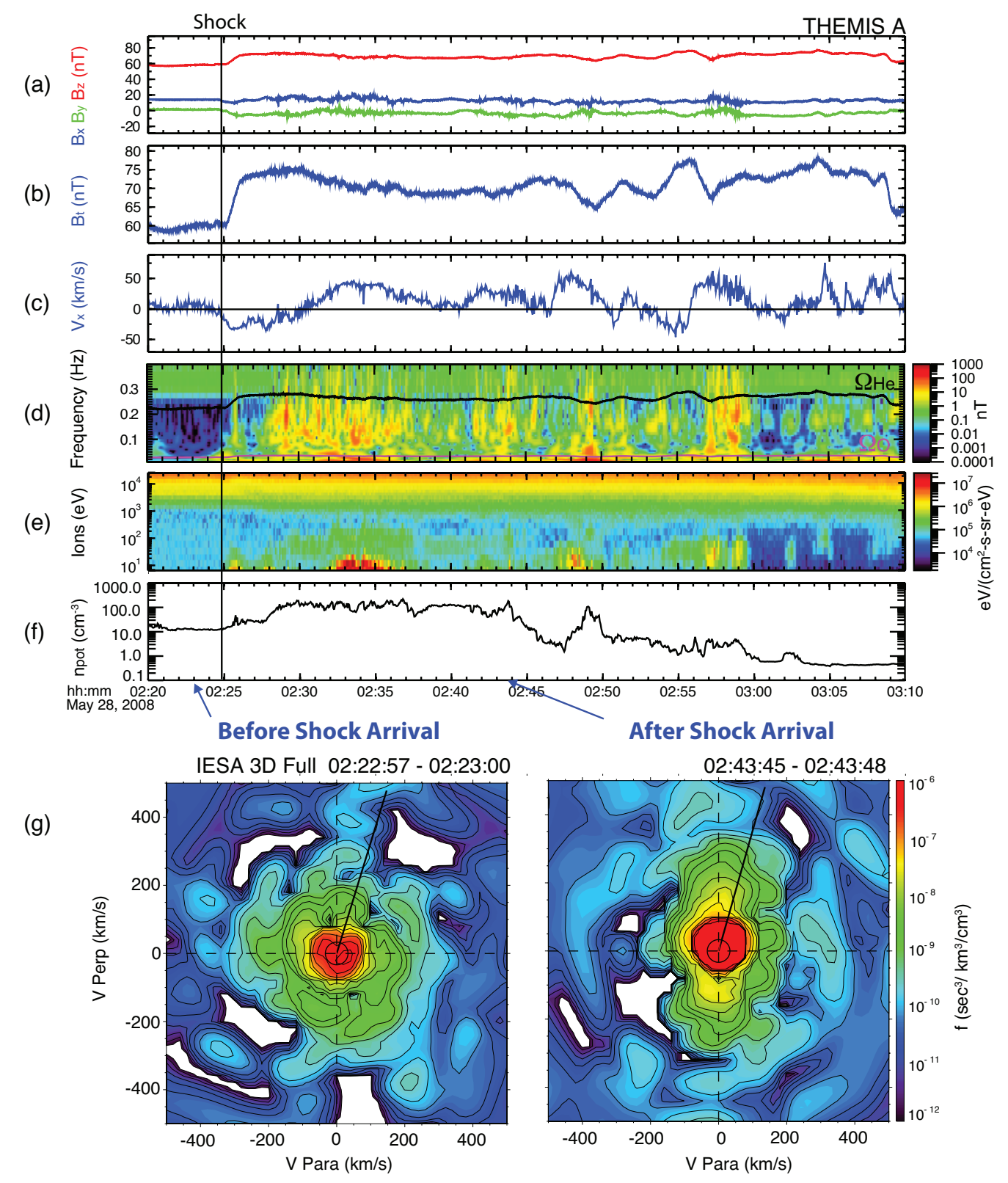

Fig. 4. THEMIS A (in the magnetosphere) observations of the EMIC wave activity and plasmaspheric plumes. From top to bottom: (a) three components of the magnetic field in GSM coordinates, (b) the magnetic field strength, (c) the X-component of the plasma flow velocity in GSM coordinates, (d) wavelet analysis result for the $B_{\mathrm{y}}$ component of the magnetic field, (e) ESA ion spectrum, (f) plasma density derived from the spacecraft potential and electron thermal speed measured by the EFI and ESA instruments, respectively, and (g) ion distributions for $3 \mathrm{~s}$ time intervals before (left) and after (right) the shock arrival. The thick black lines point toward the Sun.

anisotropic (with $T_{\perp} / T_{\|}>1$ ) at energies above $50 \mathrm{eV}$ (or $V>100 \mathrm{~km} \mathrm{~s}^{-1}$ ) after the shock passage. The displacement towards positive $V_{\text {perp }}$ in the right panel is evidence for accelerated flows. The strong anisotropy appeared at around 02:28:30 UT. The anisotropy $A_{\mathrm{i}}$ is $\sim 1$ at 02:43:45 UT, and the EMIC wave frequency should be less than $0.5 \mathrm{~Hz}$ which is consistent with the wave frequency shown in panel (d) of Fig. 4. Therefore, the observed EMIC waves were most likely excited by the anisotropic ion distributions caused by the IP shock impact. One may wonder whether this event is typical or not. The magnetic field strength compression ratio of this IP shock is 2 (calculated from the magnetic field measurement across the shock as shown in Fig. 1f) which is close to the average compression ratio of IP shocks for both solar maximum (1.97) and solar minimum (1.93) (Echer et al., 2004), therefore, this event is common. 


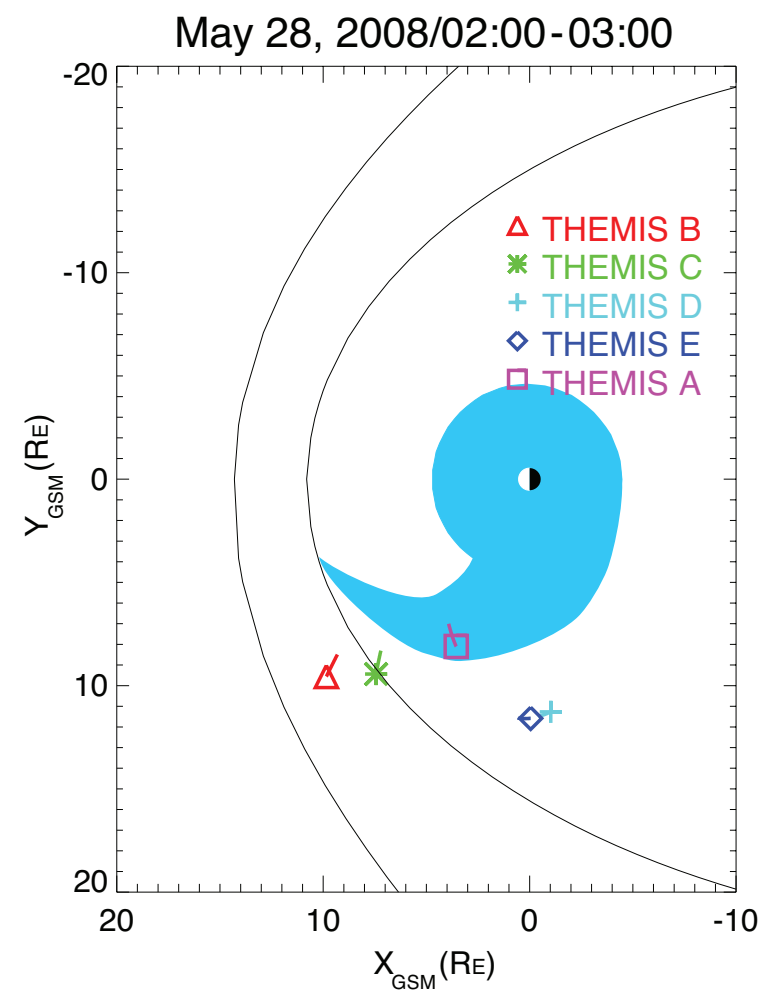

Fig. 5. A cartoon illustrating a plasmaspheric plume observed by THEMIS A (but not observed by THEMIS D and E ) in the midafternoon magnetosphere.

With multiple THEMIS spacecraft, the spatial distribution of plasmaspheric plumes can be estimated. The bottom six panels in Fig. 3 show that while THEMIS A observed an accelerated plasmaspheric plume population at $(3.8,7.5,-1.1) \mathrm{GSM} R_{\mathrm{E}}(16: 00 \mathrm{MLT}, L \approx 8.5)$ from $02: 25$ to 02:26 UT, THEMIS D and E at $(-0.7,11.4,0.6) \mathrm{GSM}$ $R_{\mathrm{E}}$ and $(0.3,11.6,0.2) \mathrm{GSM} R_{\mathrm{E}}(18: 00 \mathrm{MLT}, L \approx 11.6) \mathrm{did}$ not observe any plasmaspheric plume population during this time interval. This indicates that the dawn-side edge of the plasmaspheric plume was located between THEMIS A and $\mathrm{D}$ (or E) as illustrated in Fig. 5. THEMIS A was located in the L-MLT bin where there is a high probability to observe a plasmaspheric plume as shown in Fig. 8 of Darrouzet et al. (2008). The Kp index was 3 during this time interval which is consistent with Darrouzet et al. (2008) in that plumes are mostly observed during moderate Kp (3-6). The Dst was $-5 \mathrm{nT}$ which is also consistent with the results of Darrouzet et al. (2008) which indicated that plasmaspheric plumes were never observed for very low Dst $(<-110 \mathrm{nT})$.

\section{Conclusions}

The global magnetospheric response to an IP shock has been investigated using the THEMIS spacecraft observations. With THEMIS B and C in the magnetosheath, THEMIS A in the mid-afternoon magnetosphere, and THEMIS D and $\mathrm{E}$ in the dusk magnetosphere, the THEMIS spacecraft offer a remarkable opportunity to track the propagation of the shock and the magnetospheric response. The interaction of the transmitted IP shock with the magnetosphere has global effects. Consequently, it can affect geospace plasma significantly.

The main conclusions of this paper can be summarized as follows:

1. The interaction of an IP shock with the bow shock launched a fast shock and a discontinuity which propagated toward the Earth at speeds of $301 \mathrm{~km} \mathrm{~s}^{-1}$ and $137 \mathrm{~km} \mathrm{~s}^{-1}$, respectively.

2. THEMIS A, but not D or E, observed a plasmaspheric plume in the dayside magnetosphere. Multiple spacecraft observations indicate that the dawn-side edge of the plasmaspheric plume was located between THEMIS A and D (or E) as illustrated in Fig. 5.

3. The impact of the IP shock changed the plume properties significantly. The density increased from 10 to $100 \mathrm{~cm}^{-3}$ in $4 \mathrm{~min}$ and the ion distribution changed from an isotropic to a strongly anisotropic distribution.

4. THEMIS A also observed EMIC waves which were most likely excited by the anisotropic ion distributions caused by the IP shock impact.

Acknowledgements. This work is partly supported by the Alaska NASA EPSCoR Program. KHG was financially supported by the German Ministerium für Wirtschaft und Technologie and the Deutsches Zentrum für Luft- und Raumfahrt under grant 500C1001.

Guest Editor A. Masson thanks F. Darrouzet and two other anonymous referees for their help in evaluating this paper.

\section{References}

Anderson, B. J. and Hamilton, D. C.: Electromagnetic ion cyclotron waves stimulated by modest magnetospheric compressions, J. Geophys. Res., 98, 11369-11382, doi:10.1029/93JA00605, 1993.

Anderson, B. J., Takahashi, K., Erlandson, R. E., and Zanetti, L. J.: Pc1 pulsations observed by AMPTE/CCE in the earth's outer magnetosphere, Geophys. Res. Lett., 17, 1853-1856, doi:10.1029/GL017i011p01853, 1990.

Anderson, B. J., Erlandson, R. E., and Zanetti, L. J.: A statistical study of Pc 1-2 magnetic pulsations in the equatorial magnetosphere. I - Equatorial occurrence distributions. II - Wave properties, J. Geophys. Res., 97, 3075-3101, doi:10.1029/91JA02706, 1992.

Angelopoulos, V.: The THEMIS Mission, Space Sci. Rev., 141, 534, doi:10.1007/s11214-008-9336-1, 2008.

Auster, H. U., Glassmeier, K. H., Magnes, W., Aydogar, O., Baumjohann, W., Constantinescu, D., Fischer, D., Fornacon, K. H., Georgescu, E., Harvey, P., Hillenmaier, O., Kroth, R., 
Ludlam, M., Narita, Y., Nakamura, R., Okrafka, K., Plaschke, F., Richter, I., Schwarzl, H., Stoll, B., Valavanoglou, A., and Wiedemann, M.: The THEMIS Fluxgate Magnetometer, Space Sci. Rev., 141, 235-264, doi:10.1007/s11214-008-9365-9, 2008.

Bonnell, J. W., Mozer, F. S., Delory, G. T., Hull, A. J., Ergun, R. E., Cully, C. M., Angelopoulos, V., and Harvey, P. R.: The Electric Field Instrument (EFI) for THEMIS, Space Sci. Rev., 141, 303341, doi:10.1007/s11214-008-9469-2, 2008.

Carpenter, D. L., Smith, A. J., Giles, B. L., Chappell, C. R., and Décréau, P. M. E.: A case study of plasma structure in the dusk sector associated with enhanced magnetospheric convection, J. Geophys. Res., 97, 1157-1166, doi:10.1029/91JA01546, 1992.

Chappell, C. R.: Detached plasma regions in the magnetosphere., J. Geophys. Res., 79, 1861-1870, doi:10.1029/JA079i013p01861, 1974.

Chappell, C. R., Harris, K. K., and Sharp, G. W.: The morphology of the bulge region of the plasmasphere., J. Geophys. Res., 75, 3848-3861, doi:10.1029/JA075i019p03848, 1970.

Cornwall, J. M.: Cyclotron Instabilities and Electromagnetic Emission in the Ultra Low Frequency and Very Low Frequency Ranges, J. Geophys. Res., 70, 61-69, doi:10.1029/JZ070i001p00061, 1965.

Darrouzet, F., De Keyser, J., Décréau, P. M. E., Gallagher, D. L., Pierrard, V., Lemaire, J. F., Sandel, B. R., Dandouras, I., Matsui, H., Dunlop, M., Cabrera, J., Masson, A., Canu, P., Trotignon, J. G., Rauch, J. L., and André, M.: Analysis of plasmaspheric plumes: CLUSTER and IMAGE observations, Ann. Geophys., 24, 1737-1758, doi:10.5194/angeo-24-1737-2006, 2006.

Darrouzet, F., De Keyser, J., Décréau, P. M. E., El LemdaniMazouz, F., and Vallières, X.: Statistical analysis of plasmaspheric plumes with Cluster/WHISPER observations, Ann. Geophys., 26, 2403-2417, doi:10.5194/angeo-26-2403-2008, 2008.

Darrouzet, F., de Keyser, J., and Pierrard, V. (Eds.): The Earth's Plasmasphere, pp. 300, doi:10.1007/978-1-4419-1323-4, 2009a.

Darrouzet, F., Gallagher, D. L., André, N., Carpenter, D. L., Dandouras, I., Décréau, P. M. E., de Keyser, J., Denton, R. E., Foster, J. C., Goldstein, J., Moldwin, M. B., Reinisch, B. W., Sandel, B. R., and Tu, J.: Plasmaspheric Density Structures and Dynamics: Properties Observed by the CLUSTER and IMAGE Missions, Space Sci. Rev., 145, 55-106, doi:10.1007/s11214-0089438-9, 2009b.

Echer, E., Alves, M. V., and Gonzalez, W. D.: Geoeffectiveness of interplanetary shocks during solar minimum (1995 1996) and solar maximum (2000), Sol. Phys., 221, 361-380, doi:10.1023/B:SOLA.0000035045.65224.f3, 2004.

Elphic, R. C., Weiss, L. A., Thomsen, M. F., McComas, D. J., and Moldwin, M. B.: Evolution of plasmaspheric ions at geosynchronous orbit during times of high geomagnetic activity, Geophys. Res. Lett., 23, 2189-2192, doi:10.1029/96GL02085, 1996.

Engebretson, M. J., Peterson, W. K., Posch, J. L., Klatt, M. R., Anderson, B. J., Russell, C. T., Singer, H. J., Arnoldy, R. L., and Fukunishi, H.: Observations of two types of Pc 1-2 pulsations in the outer dayside magnetosphere, J. Geophys. Res., 107, 1451, doi:10.1029/2001JA000198, 2002.

Fairfield, D. H.: Average and unusual locations of the Earth's magnetopause and bow shock, J. Geophys. Res., 76, 6700-6716, doi:10.1029/JA076i028p06700, 1971.

Foster, J. C., Erickson, P. J., Coster, A. J., Goldstein, J., and Rich, F. J.: Ionospheric signatures of plasmaspheric tails, Geophys.
Res. Lett., 29, 1623, doi:10.1029/2002GL015067, 2002.

Fuselier, S. A., Gary, S. P., Thomsen, M. F., Claflin, E. S., Hubert, B., Sandel, B. R., and Immel, T.: Generation of transient dayside subauroral proton precipitation, J. Geophys. Res., 109, A12227, doi:10.1029/2004JA010393, 2004.

Goldstein, J., Sandel, B. R., Thomsen, M. F., Spasojević, M., and Reiff, P. H.: Simultaneous remote sensing and in situ observations of plasmaspheric drainage plumes, J. Geophys. Res., 109, A03202, doi:10.1029/2003JA010281, 2004.

Gosling, J. T., Thomsen, M. F., Bame, S. J., Elphic, R. C., and Russell, C. T.: Cold ion beams in the low latitude boundary layer during accelerated flow events, Geophys. Res. Lett., 17, 2245 2248, doi:10.1029/GL017i012p02245, 1990.

Grib, S. A., Briunelli, B. E., Dryer, M., and Shen, W.W.: Interaction of interplanetary shock waves with the bow shock-magnetopause system, J. Geophys. Res., 84, 5907-5921, doi:10.1029/JA084iA10p05907, 1979.

Horne, R. B. and Thorne, R. M.: On the preferred source location for the convective amplification of ion cyclotron waves, J. Geophys. Res., 98, 9233-9247, doi:10.1029/92JA02972, 1993.

Lemaire, J. F. and Gringauz, K. I.: The Earth's Plasmasphere, Cambridge University Press, pp. 374, doi:10.2277/0521430917, 1998.

Lepping, R. P., Acũna, M. H., Burlaga, L. F., Farrell, W. M., Slavin, J. A., Schatten, K. H., Mariani, F., Ness, N. F., Neubauer, F. M., Whang, Y. C., Byrnes, J. B., Kennon, R. S., Panetta, P. V., Scheifele, J., and Worley, E. M.: The Wind Magnetic Field Investigation, Space Sci. Rev., 71, 207-229, doi:10.1007/BF00751330, 1995.

Li, W., Thorne, R. M., Nishimura, Y., Bortnik, J., Angelopoulos, V., McFadden, J. P., Larson, D. E., Bonnell, J. W., Le Contel, O., Roux, A., and Auster, U.: THEMIS analysis of observed equatorial electron distributions responsible for the chorus excitation, $\mathrm{J}$ Geophys. Res., 115, A00F11, doi:10.1029/2009JA014845, 2010.

Maynard, N. C., Farrugia, C. J., Ober, D. M., Burke, W. J., Dunlop, M., Mozer, F. S., Rème, H., Décréau, P., and Siebert, K. D.: Cluster observations of fast shocks in the magnetosheath launched as a tangential discontinuity with a pressure increase crossed the bow shock, J. Geophys. Res., 113, A10212, doi:10.1029/2008JA013121, 2008.

McFadden, J. P., Carlson, C. W., Larson, D., Bonnell, J., Mozer, F. S., Angelopoulos, V., Glassmeier, K.-H., and Auster, U.: Structure of plasmaspheric plumes and their participation in magnetopause reconnection: First results from THEMIS, Geophys. Res. Lett., 35, L17S10, doi:10.1029/2008GL033677, 2008a.

McFadden, J. P., Carlson, C. W., Larson, D., Ludlam, M., Abiad, R., Elliott, B., Turin, P., Marckwordt, M., and Angelopoulos, V.: The THEMIS ESA Plasma Instrument and In-flight Calibration, Space Sci. Rev., 141, 277-302, doi:10.1007/s11214-008-9440-2, 2008b.

Moldwin, M. B., Howard, J., Sanny, J., Bocchicchio, J. D., Rassoul, H. K., and Anderson, R. R.: Plasmaspheric plumes: CRRES observations of enhanced density beyond the plasmapause, J. Geophys. Res., 109, A05202, doi:10.1029/2003JA010320, 2004.

Mozer, F. S.: Analysis of Techniques for Measuring DC and AC Electric Fields in the Magnetosphere, Space Sci. Rev., 14, 272313, doi:10.1007/BF02432099, 1973.

Ober, D. M., Horwitz, J. L., Thomsen, M. F., Elphic, R. C., Mc- 
Comas, D. J., Belian, R. D., and Moldwin, M. B.: Premidnight plasmaspheric "plumes", J. Geophys. Res., 102, 11325-11334, doi:10.1029/97JA00562, 1997.

Ogilvie, K. W., Chornay, D. J., Fritzenreiter, R. J., Hunsaker, F., Keller, J., Lobell, J., Miller, G., Scudder, J. D., Sittler, Jr., E. C., Torbert, R. B., Bodet, D., Needell, G., Lazarus, A. J., Steinberg, J. T., Tappan, J. H., Mavretic, A., and Gergin, E.: SWE, A Comprehensive Plasma Instrument for the Wind Spacecraft, Space Sci. Rev., 71, 55-77, doi:10.1007/BF00751326, 1995.

Přech, L., Němeček, Z., and Šafránková, J.: Response of magnetospheric boundaries to the interplanetary shock: Themis contribution, Geophys. Res. Lett., 35, L17S02, doi:10.1029/2008GL033593, 2008.

Roux, A., Perraut, S., Rauch, J. L., de Villedary, C., Kremser, G., Korth, A., and Young, D. T.: Wave-particle interactions near $\Omega_{\mathrm{He}^{+}}$observed on board GEOS 1 and 2. II - Generation of ion cyclotron waves and heating of $\mathrm{He}^{+}$ions, J. Geophys. Res., 87, 8174-8190, doi:10.1029/JA087iA10p08174, 1982.

Šafránková, J., Němeček, Z., Přech, L., Samsonov, A. A., Koval, A., and Andréeová, K.: Modification of interplanetary shocks near the bow shock and through the magnetosheath, J. Geophys. Res., 112, A08212, doi:10.1029/2007JA012503, 2007.

Samsonov, A. A., Němeček, Z., and Šafránková, J.: Numerical MHD modeling of propagation of interplanetary shock through the magnetosheath, J. Geophys. Res., 111, A08210, doi:10.1029/2005JA011537, 2006.

Samsonov, A. A., Sibeck, D. G., and Imber, J.: MHD simulation for the interaction of an interplanetary shock with the Earth's magnetosphere, J. Geophys. Res., 112, A12220, doi:10.1029/2007JA012627, 2007.

Sandel, B. R., King, R. A., Forrester, W. T., Gallagher, D. L., Broadfoot, A. L., and Curtis, C. C.: Initial results from the IMAGE extreme ultraviolet imager, Geophys. Res. Lett., 28, 1439-1442, doi:10.1029/2001GL012885, 2001.

Shen, W.-W. and Dryer, M.: Magnetohydrodynamic theory for the interaction of an interplanetary double-shock ensemble with the earth's bow shock., J. Geophys. Res., 77, 4627-4644, doi:10.1029/JA077i025p04627, 1972.

Singh, A. K., Singh, R. P., and Siingh, D.: State studies of Earth's plasmasphere: A review, Planet. Space Sci., 59, 810-834, doi:10.1016/j.pss.2011.03.013, 2011.
Takahashi, K., Bonnell, J., Glassmeier, K.-H., Angelopoulos, V., Singer, H. J., Chi, P. J., Denton, R. E., Nishimura, Y., Lee, D.H., Nosé, M., and Liu, W.: Multipoint observation of fast mode waves trapped in the dayside plasmasphere, J. Geophys. Res. 115, A12247, doi:10.1029/2010JA015956, 2010.

Usanova, M. E., Mann, I. R., Rae, I. J., Kale, Z. C., Angelopoulos, V., Bonnell, J. W., Glassmeier, K., Auster, H. U., and Singer, H. J.: Multipoint observations of magnetospheric compressionrelated EMIC Pc1 waves by THEMIS and CARISMA, Geophys Res. Lett., 35, L17S25, doi:10.1029/2008GL034458, 2008.

Viñas, A. F. and Holland, M. P.: Shock and Discontinuities Analysis Tool (SDAT), EOS Trans. AGU, 86, Jt. Assem. Suppl., SH51B10, 2005.

Viñas, A. F. and Scudder, J. D.: Fast and optimal solution to the 'Rankine-Hugoniot problem', J. Geophys. Res., 91, 39-58, doi:10.1029/JA091iA01p00039, 1986.

Völk, H. J. and Auer, R.-D.: Motions of the bow shock induced by interplanetary disturbances, J. Geophys. Res., 79, 40-48, doi:10.1029/JA079i001p00040, 1974.

Young, D. T., Perraut, S., Roux, A., de Villedary, C., Gendrin, R., Korth, A., Kremser, G., and Jones, D.: Wave-particle interactions near $\Omega_{\mathrm{He}^{+}}$observed on GEOS 1 and 2. I - Propagation of ion cyclotron waves in $\mathrm{He}^{+}$-rich plasma, J. Geophys. Res., 86, 6755-6772, doi:10.1029/JA086iA08p06755, 1981.

Zhang, H., Zong, Q., Sibeck, D. G., Fritz, T. A., McFadden, J. P., Glassmeier, K., and Larson, D.: Dynamic motion of the bow shock and the magnetopause observed by THEMIS spacecraft, J. Geophys. Res., 114, A00C12, doi:10.1029/2008JA013488, 2009.

Zhang, J.-C., Kistler, L. M., Mouikis, C. G., Klecker, B., Sauvaud, J.-A., and Dunlop, M. W.: A statistical study of EMIC wave-associated $\mathrm{He}^{+}$energization in the outer magnetosphere: Cluster/CODIF observations, J. Geophys. Res., 116, A11201, doi:10.1029/2011JA016690, 2011.

Zhuang, H. C., Russell, C. T., Smith, E. J., and Gosling, J. T.: Three-dimensional interaction of interplanetary shock waves with the bow shock and magnetopause - A comparison of theory with ISEE observations, J. Geophys. Res., 86, 5590-5600, doi:10.1029/JA086iA07p05590, 1981. 